\title{
Jaw exercise therapy for the treatment of trismus in head and neck Cancer: a prospective three-year follow-up study
}

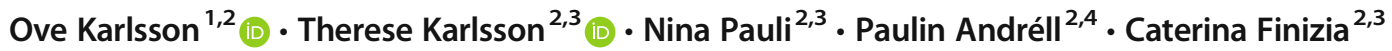

Received: 7 October 2019 / Accepted: 6 May 2020 / Published online: 24 November 2020

(C) The Author(s) 2020

\begin{abstract}
Purpose This study aims to examine effects of jaw exercise on trismus 3 years following completion of a post-radiotherapy jaw exercise intervention.

Methods Prospective study including 50 patients with head-and-neck cancer receiving radiotherapy and/or chemotherapy, plus a matched control group. The intervention group underwent 10 weeks of jaw exercise training. Patients were followed pre-and postintervention and 3 years postintervention completion. Outcome measures were maximal interincisal opening (MIO), trismusrelated symptoms, and health-related quality-of-life as measured by Gothenburg Trismus Questionnaire, EORTC QLQ-C30, and EORTC QLQ-H\&N35.

Results The intervention group had a statistically significantly higher mean MIO compared with the control group (40.1 mm and $33.9 \mathrm{~mm}$, respectively, $p<0.001$ ), reported less trismus-related problems and had an improved health-related quality-of-life when compared with the control group at the 3-year follow-up. These differences were all statistically significant.

Conclusion Jaw exercise therapy resulted in increased MIO, less trismus-related symptoms, and improved health-related qualityof-life. Jaw exercise therapy should be initiated early, in a structured manner and continued long-term.
\end{abstract}

Keywords Trismus $\cdot$ Radiotherapy $\cdot$ Health-related quality of life $\cdot$ Exercise therapy $\cdot$ Mouth opening ability

\section{Introduction}

Trismus is defined as reduced mouth opening, Maximum Interincisal Opening (MIO) $\leq 35 \mathrm{~mm}[1]$, and can be caused by benign disorders, infections in the oral cavity, trauma, and malignant disorders [2]. Common symptoms associated with

Therese Karlsson

therese.karlsson.2@gu.se

1 Department of Anaesthesiology, Institute of Clinical Science, Sahlgrenska Academy at the University of Gothenburg, Sahlgrenska University Hospital, Gothenburg, Sweden

2 Department of Otorhinolaryngology, Region Västra Götaland, Sahlgrenska University Hospital, Gothenburg, Sweden

3 Department of Otorhinolaryngology, Head and Neck Surgery, Institute of Clinical Sciences, Sahlgrenska Academy at the University of Gothenburg, Sahlgrenska University Hospital, Gothenburg, Sweden

4 Department of Molecular and Clinical Medicine/Pain Center, Institute of Medicine, Sahlgrenska Academy at the University of Gothenburg, Göteborg, Sweden trismus besides limited mouth opening are pain, difficulties with chewing and swallowing, and poor oral hygiene. Subsequently, trismus has a negative impact on both mental health and health-related quality of life (HRQL) [2].

In patients with head and neck cancer ( $\mathrm{HNC})$, trismus is a common symptom with a reported incidence after oncologic treatment of up to $40 \%$ [3]. The majority of the HNC patients are treated surgically or with radiotherapy and sometimes with additional chemotherapy for advanced stage tumors according to Swedish Cancer Guidelines [4].

Symptom trajectory reveals a typical worsening of the condition immediately after treatment, peaking 6-9 months posttreatment [5]. Spontaneous trismus recovery can be expected to a certain degree, but for the majority of afflicted patients, status remains unchanged due to the posttreatment development of tissue fibrosis in the masticatory muscles and temporomandibular joint. There is no standardized treatment for radiotherapy-induced trismus, and although several studies have assessed exercise intervention, these studies included small study populations [6-8]. A recently published study by this research group reported that structured exercise intervention with jaw mobilizing devices improved mouth 
opening, trismus-related symptoms, and HRQL at 2 years following completion of jaw exercise training [9].

However, data for longer term follow-up is lacking. Hence, this study aims to investigate the effects of mouth opening, trismus-related symptoms, and HRQL after structured mouth opening intervention in HNC patients with trismus at 3 years following jaw exercise therapy.

\section{Material and methods}

\section{Participants}

Patients with newly diagnosed HNC tumors and location expected to develop trismus were included in the study between 2007 and 2012 from five medical centers in the Västra Götaland region, Sweden (Table 1). Inclusion criteria were

Table 1 Patient characteristics in the intervention group and the control group at baseline

\begin{tabular}{|c|c|c|}
\hline & $\begin{array}{l}\text { Intervention group } \\
*_{n}=50\end{array}$ & $\begin{array}{l}\text { Control group } \\
*_{n}=50\end{array}$ \\
\hline \multirow{3}{*}{ Age mean (range) } & Mean (range) & Mean (range) \\
\hline & $57.9(30-75)$ & $58.0(29-80)$ \\
\hline & $n(\%)$ & $n(\%)$ \\
\hline \multicolumn{3}{|l|}{ Gender } \\
\hline Male & $31(62)$ & $31(62)$ \\
\hline Female & $19(38)$ & $19(38)$ \\
\hline \multicolumn{3}{|l|}{ Treatment regimen } \\
\hline Radiotherapy only & $7(14)$ & $8(16)$ \\
\hline Radiochemotherapy & $39(80)$ & $38(76)$ \\
\hline Radiotherapy + surgery & $4(8)$ & $4(8)$ \\
\hline \multicolumn{3}{|l|}{ Tumor location } \\
\hline Oropharynx & $38(76)$ & $38(76)$ \\
\hline Tumor colli & $6(12)$ & $6(12)$ \\
\hline Oral cavity & $1(2)$ & $1(2)$ \\
\hline Nasopharynx & $5(10)$ & $5(10)$ \\
\hline \multicolumn{3}{|l|}{ Staging } \\
\hline 1 & $1(2)$ & $0(0)$ \\
\hline 2 & $8(18)$ & $4(9)$ \\
\hline 3 & $8(18)$ & $12(27)$ \\
\hline 4 & $27(61)$ & $28(64)$ \\
\hline \multicolumn{3}{|l|}{ ACE-27 } \\
\hline No comorbidity & $29(58)$ & $20(40)$ \\
\hline Mild comorbidity & $13(26)$ & $18(36)$ \\
\hline Moderate comorbidity & $7(14)$ & $10(20)$ \\
\hline Severe comorbidity & $1(2)$ & $2(4)$ \\
\hline
\end{tabular}

$A C E-27$, Adult Comorbidity Evaluation

*There was no statistically significant difference (on any variable) between the intervention group and the control group radiation therapy with or without chemotherapy and development of trismus after oncologic treatment.

Patients with difficulties filling out questionnaires, edentulous patients, and patients with poor general health (including but not limited to for instance dementia or substance abuse) were excluded as well as patient undergoing surgical treatment and who had trismus prior to starting treatment. Patients residing in Gothenburg underwent regular clinical evaluation by one single oral surgeon at the Department of Oral and Maxillofacial Surgery, Institute of Odontology and Public Dental Service, Gothenburg, Sweden and those who developed trismus were invited to participate in a 10-week intervention program performed by the same oral surgeon [7].

The control group consists of patients living outside the Gothenburg catchment area and was matched according to tumor location, tumor stage, gender, age (within a 5-year interval), comorbidity, and radiation dose. The control group was followed up with appointments according to local guidelines and MIO was measured by the local hospital dentist. However, no structured intervention program for trismus existed during the study period. Any attempt of improving mouth opening, structured or otherwise, was registered by the study coordinator [7].

\section{Outcome measures, assessment, and questionnaires}

The primary endpoint in this study was the MIO measured in millimeters, which was measured using a ruler with the patient sitting in an upright position. MIO was measured as the maximal distance between the edges of the incisors of the mandible and the maxilla, expressed in millimeters. Patients were assessed before and after exercise intervention and after 2 and 3 years, respectively. Secondary endpoints were HRQL and trismus-related symptoms assessed by Patient-Reported Outcome Measures (PROM) instruments, including The European Organization for Research and Treatment of Cancer Core Questionnaire (EORTC QLQ-C30) and the related module for Head and Neck Questionnaire in EORTC (EORTC QLQ-HN35) and Gothenburg Trismus Questionnaire (GTQ) [10-12].

The patients' comorbidity was assessed according to the Adult Comorbidity Evaluation 27 (ACE-27) [13-15]. Tumors were classified and staged according to the TNM system of classification of malignant tumors determined by the Union for International Cancer Control [16].

\section{Trismus intervention}

Patients in the intervention group and the 50 matched controls were enrolled 3-6 months after receiving radiotherapy. The structured trismus exercise was performed with a jaw mobilizing device during 10 weeks. The devices used in this study were the TheraBite $\AA$ jaw device or the Engström jaw device, 
Fig. 1 [7]. A study by Pauli et al. showed no significant difference between the Therabite ${ }^{\circledR}$ and Engström jaw mobilizers at 3 months postintervention and is considered to be equivalent devices [17]. All patients in the intervention group received written and oral instructions as well as a demonstration of the device by the same oral surgeon. The patients started the exercise with warm-up movements and stretching for $30 \mathrm{~s}$, if possible, using a jaw mobilizing device five times daily. The exercise consisted of active movements, biting against resistance, and passive, stretch movements of the jaw. MIO was evaluated by the same oral surgeon before and after intervention and thereafter at 1,2, and 3 years postintervention. After the 10-week of exercise intervention, the patients were instructed to continue the exercise at least three times weekly or more often if needed. A more precise definition of the exercise program is outlined in Pauli et al., 2014 [7].

\section{Patient-reported outcome}

\section{EORTC QLQ-C30 and EORTC QLQ-H\&N35}

The EORTC QLQ-C30 is a cancer-specific questionnaire that assesses HRQL in patients with cancer [18]. For functional domains and the global quality of life domain, scores range from 0 to 100 , where a high score is equal to a high level of functioning or a high level of global quality of life. For single items, the scores also range from 0 to 100 , but a higher score is indicative of a higher symptom burden. To address additional symptoms associated specifically with $\mathrm{HNC}$, a complementary 35-item module was used, the EORTC QLQ-H\&N35. As described before in symptom scales and single items, a score of 100 indicates the worst possible symptoms and 0 indicates no symptoms $[10,11][19]$.

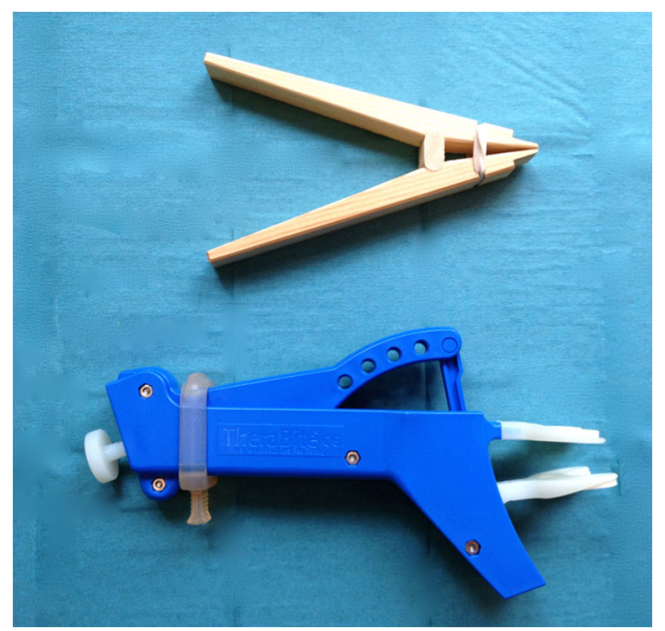

Fig. 1 Top, Engström jaw device. Bottom, Therabite ${ }^{\circledR}$ jaw device

\section{Gothenburg trismus questionnaire (GTQ)}

The GTQ is a trismus-specific self-administered questionnaire, well accepted by patients and has shown good validity and reliability [12]. It is composed of three domains containing the following 13 items: jaw-related problems (six items), eating limitations (four items), and muscular tension (three items). The remaining eight items are retained as single items addressing facial pain and pain associated with trismus and if trismus is affecting work, leisure, or social life. The domains and single items range from 0 to 100 , where 100 equates to maximum symptomatology and 0 represents no symptoms.

\section{Statistical methods}

Descriptive statistics were calculated according to standard procedures. For comparison between groups, Fisher's exact test was used for dichotomous variables and the MantelHaenszel $X^{2}$ exact test was used for ordered categorical variables and $\mathrm{X}^{2}$ exact test was used for non-ordered categorical variables. For comparison between groups, the MannWhitney U test was used for continuous variables. Continuous variables are reported using mean and confidence intervals. All tests are two-tailed and conducted at a 5\% significance level.

\section{Results}

\section{Patient characteristics}

Patient characteristics are presented in Table 1. Both the intervention group and the control group developed trismus within 9 months from radiotherapy termination of which the majority presented with trismus within 3-6 months. In the intervention group $(n=50)$, three patients were lost at 3-year follow-up (deceased $n=2$, unspecified $n=1)$. In the control group ( $n=$ 50), seven patients were lost at 3-year follow-up (deceased $n=6$, unspecified $n=1$ ).

\section{Jaw exercise therapy}

The intervention group and the control group trained to varying degrees during the follow-up period. At 3-year follow-up, 41 of the $47(87 \%)$ intervention patients no longer had trismus (i.e., > $35 \mathrm{~mm}$ ) and 32 of 47 (68\%) had continued performing the exercises. Of the patients still exercising at 3-year followup, 26 of $32(81 \%)$ no longer had trismus. The exercise frequency in the intervention group was as follows: one trained occasionally, 24 trained once a day, and seven trained two to four times a day. A total of 19 out of 32 (59\%) estimated their training as very effective. In the control group, 23 of the 43 
(53\%) patients no longer had trismus at 3-year follow-up. Fourteen of 43 (33\%) patients were exercising, and seven of $14(50 \%)$ no longer had trismus. The exercise frequency in the control group was as follows: three trained occasionally, seven trained once a day, and four trained two to four times a day, with four of 14 (29\%) estimated their training as very effective.

\section{Maximum interincisal opening (MIO)}

At the 3-year follow-up, the intervention group had a statistically significant improved mean MIO (40.1 mm), compared with the control group $(33.9 \mathrm{~mm}) p<0.001$, Fig. 2 .

\section{Gothenburg trismus questionnaire (GTQ)}

After exercise intervention, the intervention group reported a statistically significant improvement in three domains, jawrelated problems, eating limitations, and muscular tension as well as in the questions about facial pain right now, compared with the control group (Table 2). At the 3-year followup, the intervention group reported statistically different improvements in all domains and items of the GTQ questionnaire.

\section{EORTC QLQ-C30}

Immediately after exercise intervention, the control group and intervention group reported similar scores, with the only statistically significant difference noted in Global quality of life. However, at the 3-year follow-up, the intervention group had improved in all functional domains and most single items compared with the control group, resulting in statistical differences between the groups in 14 out of 15 items (Table 3 ). The greatest improvement was found in the domain Global quality of life $(\Delta 28)$.

\section{EORTC QLQ-H\&N35}

Only mouth opening differed significantly between the groups postintervention. However, at the 3-year follow-up, the intervention group reported higher HRQL in 13 out of 14 items compared with the control group (Table 4).

\section{Discussion}

This, to date, longest prospective study investigating the effects of jaw exercise in irradiated HNC patients with trismus found that patients receiving early and structured jaw exercise

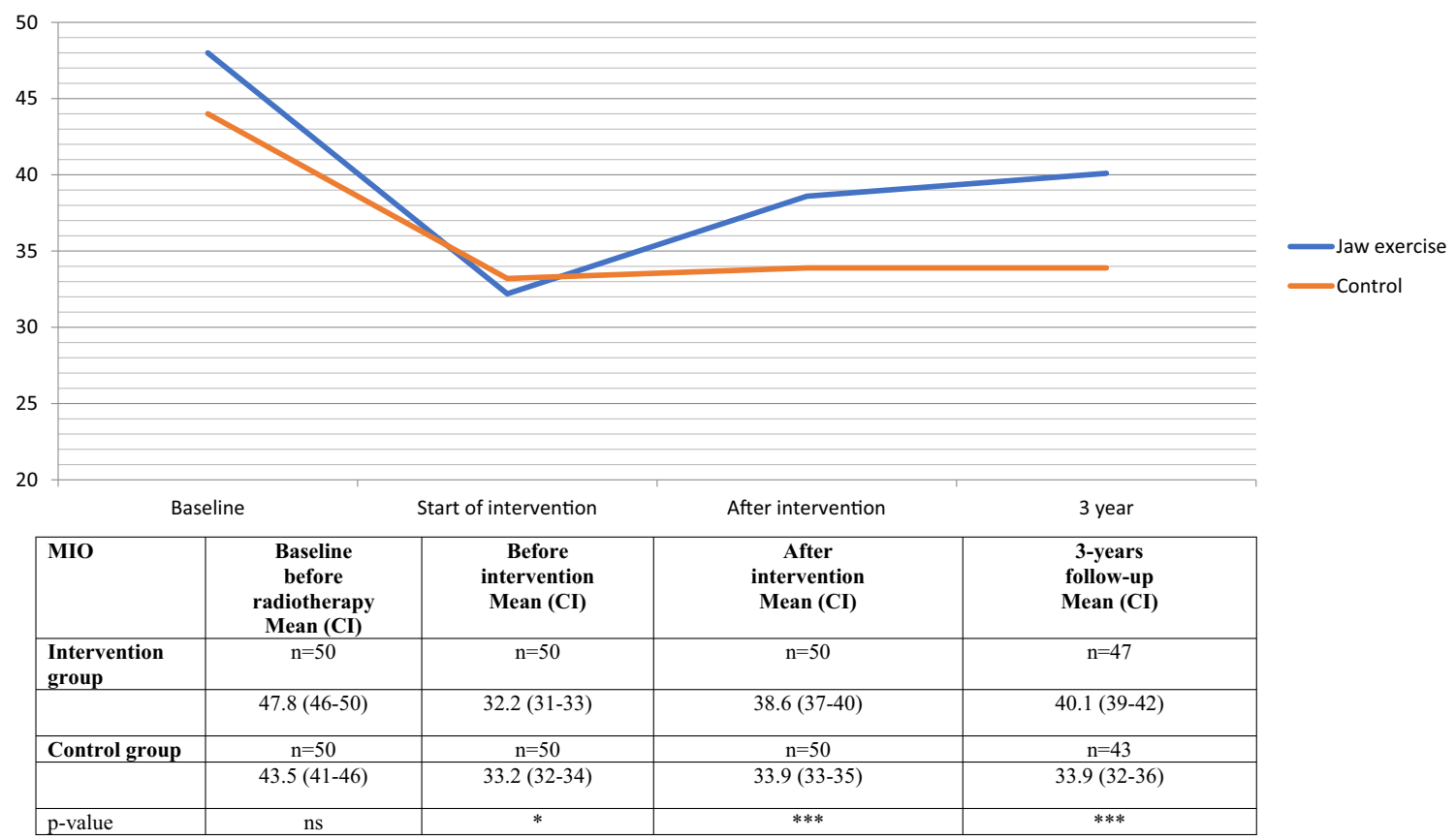

MIO; Maximal interincisal opening. ${ }^{*} \mathrm{p}<0.05, * * * \mathrm{p}<0.001, \mathrm{p}$-value between the intervention group and the control group at each given assessment.

Fig. 2 Maximal interincisal opening, mean value, and 95\% confidence interval $(\mathrm{CI})$ for head and neck cancer patients over time, from baseline to 3 -year follow-up. MIO, maximal interincisal opening. * $p<0.05$, ***p $<$
$0.001, p$ value between the intervention group and the control group at each given assessment 
Table 2 GTQ-score for head and neck cancer patients before and after intervention and 3-year follow-up

\begin{tabular}{|c|c|c|c|c|c|c|c|c|c|}
\hline \multirow[b]{2}{*}{ GTQ } & \multicolumn{3}{|c|}{ Before intervention } & \multicolumn{3}{|c|}{ After intervention } & \multicolumn{3}{|c|}{ 36-months follow-up } \\
\hline & $\begin{array}{l}\mathrm{I}, n=50 \\
\text { mean }(\mathrm{CI})\end{array}$ & $\begin{array}{l}\mathrm{C}, n=50 \\
\text { mean }(\mathrm{CI})\end{array}$ & $\mathrm{p}$ & $\begin{array}{l}\mathrm{I}, n=50 \\
\text { mean }(\mathrm{CI})\end{array}$ & $\begin{array}{l}\mathrm{C}, n=50 \\
\text { mean }(\mathrm{CI})\end{array}$ & $\mathrm{p}$ & $\begin{array}{l}\mathrm{I}, n=47 \\
\text { mean }(\mathrm{CI})\end{array}$ & $\begin{array}{l}\mathrm{C}, n=43 \\
\text { mean }(\mathrm{CI})\end{array}$ & $p$ \\
\hline Jaw-related problems & $41.4(36-47)$ & $41.5(35-48)$ & ns & $22.9(17-29)$ & $43.1(37-49)$ & $* * *$ & $9.0(6-12)$ & $46.0(39-53)$ & $* * *$ \\
\hline Eating limitations & $46.5(37-56)$ & $40.0(33-47)$ & ns & $28.1(21-35)$ & $39.5(33-46)$ & * & $4.9(3-7)$ & $46.4(38-55)$ & $* * *$ \\
\hline Muscular tension & $26.3(22-31)$ & $23.8(18-29)$ & ns & $13.2(10-17)$ & $27.5(22-33)$ & $* * *$ & $7.8(5-11)$ & $40.3(33-47)$ & $* * *$ \\
\hline Facial pain right now & $24.3(18-31)$ & $20.7(14-27)$ & ns & $9.0(4-14)$ & $20.7(15-26)$ & $* * *$ & $2.5(0-4)$ & $20.2(15-26)$ & $* * *$ \\
\hline Facial pain worst last month & $43.0(36-51)$ & $40.3(33-48)$ & ns & $22.7(16-29)$ & $30.7(24-38)$ & ns & $5.0(3-7)$ & $27.5(21-34)$ & $* * *$ \\
\hline Facial pain average & $38.3(32-45)$ & $35.3(28-43)$ & ns & $21.0(15-27)$ & $30.0(23-37)$ & ns & $5.0(2-7)$ & $25.6(19-32)$ & $* * *$ \\
\hline Facial pain social, leisure, and family activities & $24.0(16-32)$ & $23.5(16-31)$ & ns & $15.0(7-23)$ & $20.0(13-27)$ & ns & $0.5(0-2)$ & $20.9(14-28)$ & $* * *$ \\
\hline Facial pain affecting ability to work & $25.0(17-33)$ & $23.5(15-32)$ & ns & $13.5(6-21)$ & $21.0(14-28)$ & * & $1.1(0-3)$ & $18.0(12-25)$ & $* * *$ \\
\hline Limitation in opening mouth & $49.0(43-55)$ & $45.0(36-54)$ & ns & $33.0(26-40)$ & $40.0(33-47)$ & ns & $15.4(11-20)$ & $43.0(34-52)$ & $* * *$ \\
\hline LOM social, leisure and family activities & $24.0(18-30)$ & $24.5(17-32)$ & ns & $16.5(8-25)$ & $26.5(20-33)$ & $* *$ & $2.7(0-5)$ & $22.1(15-29)$ & $* * *$ \\
\hline LOM affecting ability to work & $24.5(16-33)$ & $25.0(17-33)$ & ns & $14.0(6-22)$ & $22.0(15-30)$ & $*$ & $2.1(0-5)$ & $22.1(15-29)$ & $* * *$ \\
\hline
\end{tabular}

$n s$, not statistically significant; $I$, intervention group; $C$, control group; GTQ, Gothenburg Trismus Questionnaire; $C I$, $95 \%$ confidence interval; $H N C$, head and neck cancer; Domains and single items range $0-100$, where 100 indicate maximal amount of symptoms and 0 is equal to no symptoms. $P$ values for analysis of statistical significant difference in mean scores between the intervention group and the control group, before and after intervention and at 3-year follow-up

$* * * * * * p<0.05, p<0.01, p<0.001$

therapy had a significantly higher MIO, reported significantly less trismus-related symptom (as measured by GTQ), and had a higher HRQL compared with the control group at 3 years follow-up.

A recent review by Kamstra et al. found 211 articles originating from 20 studies of trismus and the effects of jaw exercise therapy [20]. The review found that 12 studies appeared to have some effect, but due to various limitations, the authors concluded that no clinical guidelines could be given following the review. A recurring issue is that patients are not evaluated long-term making conclusions of efficacy difficult to draw. In this study, however, with the longest follow-up to date, $87 \%$ of patients receiving structured jaw exercise therapy no longer had trismus at 3 years (i.e., $\mathrm{MIO} \leq 35 \mathrm{~mm}$ ). Additionally, apart from reporting statistically significant better HRQL on all items in EORTC QLQ-H\&N35 compared with the control group at the 3-year follow-up, the intervention group reported data comparable with healthy individuals (Table 3 ) regarding social contact, sexuality, and teeth problems [21]. The control group on the other hand, in fact reported worse HRQL in all questionnaire items when compared with the pooled HRQLdata of all HNC survivors at three years [21]. Thus, the negative impact of untreated trismus on HRQL is highlighted and this study finds that jaw exercise therapy appears effective long term for treating symptoms and improving HRQL.

A previous study by Pauli et al. reported the MIO, GTQ, and HRQL data for this cohort at 2 years posttraining intervention [9]. When comparing the 3-year data with the twoyear follow-up by Pauli et al., some points are worth highlighting. Firstly, mouth opening ability as measured by MIO appears unchanged for both the intervention and control group between the two time-points. Additionally, the symptom burden recorded by GTQ also remains stable. However, in contrast, HRQL according to EORTC QLQ-C30 continues to improve in the intervention group, with significant differences in an additional six domains/items (physical function, emotional function, cognitive function, fatigue, nausea and vomiting, pain) at 3 years compared with the control group, as opposed to significant difference in only three items (role function, social function, and global quality of life) at the twoyear follow-up. A similar pattern was seen in EORTC QLQH\&N35 where only four items (speech, social contact, teeth problems, and mouth opening) were significantly better in the intervention group at 2 years compared with the control group, whereas at 3 years statistically significant differences were found between the groups in all items. The static values of MIO long term may be explained by remaining fibrosis, whereas the improvement in HRQL despite unchanged MIO might reflect the long-term effects of reduced trismus on other aspects of life, which cannot be as instantly measured as MIO.

Effective jaw exercise training involves mainly three aspects highlighted in this study. Firstly, exercising early and in a structured manner when trismus first develops appears pivotal. This was concluded as despite $33 \%$ of the control group also ended up performing jaw exercise training due to problematic trismus (albeit unstructured), the mean MIO did not improve to the same extent as the intervention group. Moreover, only 53\% of control group patients were free of 


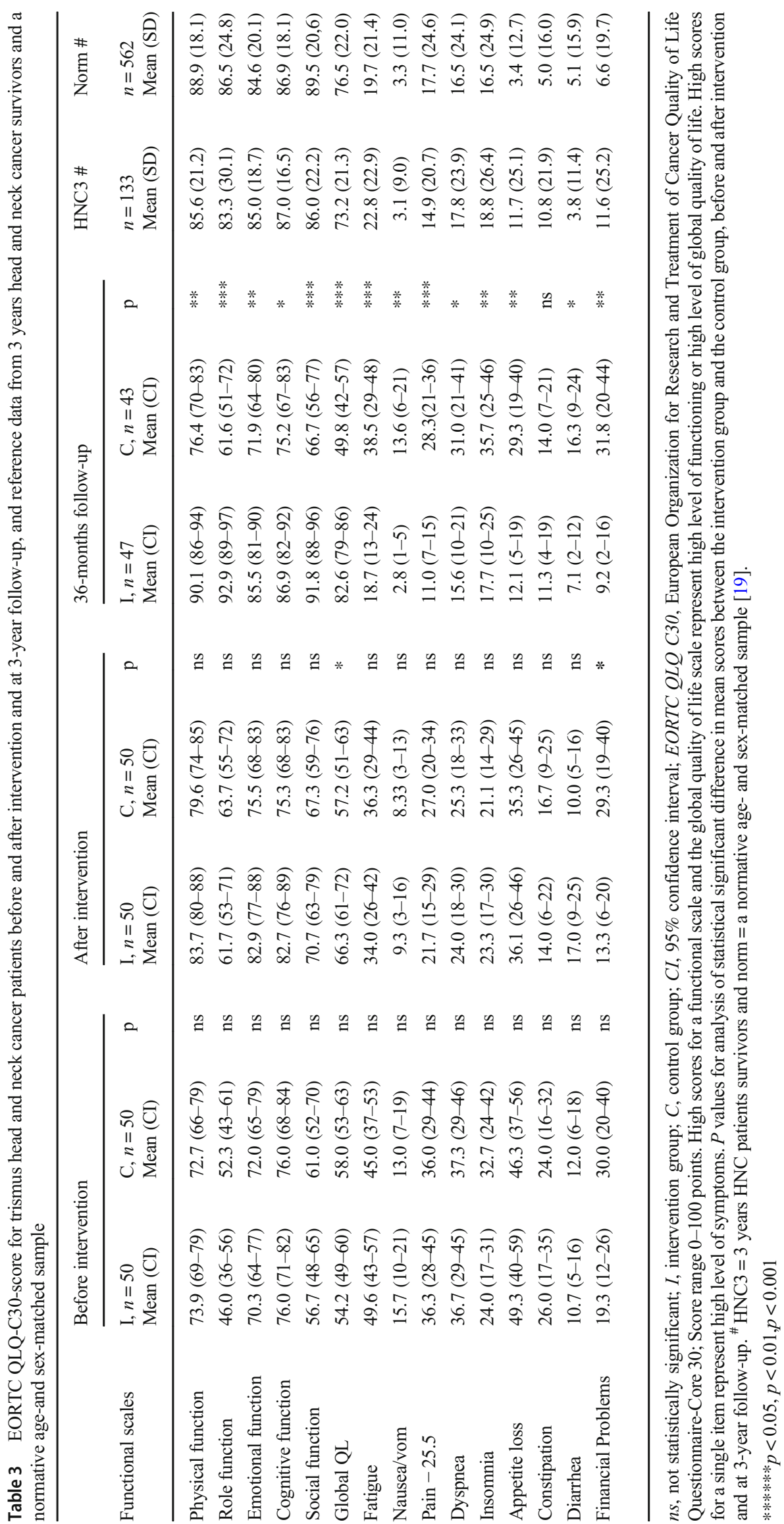


Table 4 EORTC QLQ-H\&N35-score for head and neck cancer patients before and after intervention and 3-year follow-up, and reference data from 3 years head and neck cancer survivors and a normative age-and sex-matched sample

\begin{tabular}{|c|c|c|c|c|c|c|c|c|c|c|c|}
\hline \multirow{2}{*}{$\begin{array}{l}\text { EORTC } \\
\text { QLQ-H\&N35 } \\
\text { Symptom scales }\end{array}$} & \multicolumn{3}{|c|}{ Before intervention } & \multicolumn{3}{|c|}{ After intervention } & \multicolumn{3}{|c|}{ 36-months follow-up } & \multirow{2}{*}{$\begin{array}{l}\text { HNC3 \# } \\
n=133 \\
\text { Mean (SD) }\end{array}$} & \multirow{2}{*}{$\begin{array}{l}\text { Norm \# } \\
n=562 \\
\text { Mean (SD) }\end{array}$} \\
\hline & $\begin{array}{l}\mathrm{I}, n=50 \\
\text { Mean (CI) }\end{array}$ & $\begin{array}{l}\text { C, } n=50 \\
\text { Mean }(\mathrm{CI})\end{array}$ & $\mathrm{p}$ & $\begin{array}{l}\mathrm{I}, n=50 \\
\text { Mean }(\mathrm{CI})\end{array}$ & $\begin{array}{l}\text { C, } n=50 \\
\text { Mean }(\mathrm{CI})\end{array}$ & $\mathrm{p}$ & $\begin{array}{l}\mathrm{I}, n=47 \\
\text { Mean }(\mathrm{CI})\end{array}$ & $\begin{array}{l}\text { C, } n=43 \\
\text { Mean }(\mathrm{CI})\end{array}$ & $\mathrm{p}$ & & \\
\hline tal pamt & 5 & $-47)$ & ns & $30.0(23-37)$ & $33.8(27-41)$ & ns & $.4(11-20)$ & $28.9(22-36)$ & $* *$ & 14.5 & 3.0 \\
\hline wallowing & $43.6(36-51)$ & $8.8(31-47)$ & ns & $32.3(25-39)$ & $35.4(27-44)$ & ns & $4(12-24)$ & $38.5(30-47)$ & $* * *$ & $10.9(19.6)$ & $2.0(7.2)$ \\
\hline enses & 37.0 & 39.7 & ns & 26. & 32 & ns & 23) & 32.2 & $* *$ & 20 & $5.1)$ \\
\hline Speech & $30.9(24-38)$ & $28.0(21-35)$ & ns & 19.1 & 25.4 & ns & 14) & 28.9 & $*$ & 12 & 2) \\
\hline ocial eating & $45.4(37-54)$ & $42.3(35-50)$ & ns & $31.8(25-38)$ & $42.3(34-50)$ & ns & 14.9 & 39.9 & $* * *$ & $11.7(22.6)$ & $2.7(10.0)$ \\
\hline Social contact & $19.6(12-27)$ & $16.4(10-22)$ & ns & $10.0(5-15)$ & $16.0(10-23)$ & ns & $2.7(1-4)$ & $24.5(17-32)$ & $* * *$ & $7.6(14.7)$ & $3.8(10.6)$ \\
\hline Sexuality & $56.6(47-66)$ & $59.7(49-71)$ & ns & $45.1(34-56)$ & $47.3(37-58)$ & ns & $25.0(17-33)$ & $44.6(34-55)$ & $*$ & $28.8(36.3)$ & $26.1(33.6)$ \\
\hline Teeth problems & $24.0(16-32)$ & $24.7(16-33)$ & ns & 20.7 (13-29) & $29.9(21-39)$ & ns & $12.1(6-18)$ & $35.7(25-47)$ & $* * *$ & $21.4(32.3)$ & $10.1(21.4)$ \\
\hline Opening mouth & $44.0(37-51)$ & $45.3(37-54)$ & ns & $30.7(21-40)$ & $45.3(37-54)$ & $* *$ & $15.6(10-21)$ & $46.5(36-57)$ & $* * *$ & $17.6(29.3)$ & $1.8(10.8)$ \\
\hline Dry mouth & $79.3(72-87)$ & $82.7(75-91)$ & ns & $71.3(63-80)$ & $78.2(70-87)$ & ns & $52.2(42-62)$ & $75.2(67-84)$ & $* * *$ & $47.3(36.3)$ & $12.3(22.3)$ \\
\hline Sticky saliva & $66.7(56-77)$ & $69.4(60-79)$ & ns & $54.7(45-65)$ & $62.6(53-73)$ & ns & $32.6(25-41)$ & $55.8(46-65)$ & $* * *$ & $18.6(28.4)$ & $6.9(17.5)$ \\
\hline Coughing & $32.0(22-42)$ & $30.0(21-39)$ & ns & $28.0(19-37)$ & $32.0(22-42)$ & ns & $17.7(12-24)$ & $31.8(22-42)$ & $*$ & $17.3(24.6)$ & $16.8(24.4)$ \\
\hline Feeling ill & $31.3(22-41)$ & $29.3(21-37)$ & ns & $20.7(12-29)$ & $22.9(14-31)$ & ns & $11.3(6-17)$ & $30.2(21-40)$ & $* *$ & $10.8(20.0)$ & $11.3(21.5)$ \\
\hline Pain killers & $67.3(54-81)$ & $62.0(48-76)$ & ns & $42.0(28-56)$ & $40.0(26-54)$ & ns & $27.7(14-41)$ & $44.2(26-62)$ & ns & No data & No data \\
\hline
\end{tabular}

$n s$, not statistically significant; $I$, intervention group; $C$, control group; $C I, 95 \%$ confidence interval; EORTC QLQ-H\&N35, European Organization for Research and Treatment of Cancer Quality of Life Questionnaire Head and Neck 35; HNC, head and neck cancer. ${ }^{\#}$ HNC3 = HNC patients survivors at 3 years, Norm $=$ a normative age- and sex-matched sample [19]. Score range $0-100$ points. High scores for a single item represent high level of symptoms. $P$ values for analysis of statistical significant difference in mean scores between the intervention group and the control group, before and after intervention and at 3-year follow-up

$* p<0.05, * * p<0.01, * * * p<0.001$

trismus at 3 years as opposed to $87 \%$ in the intervention group. Lastly, many patients continued to exercise following the completion of the initial 10 weeks of intervention (68\%), in contrast to other studies which have previously shown that adherence to independent and unsupervised training may be poor [22]. The high exercise compliance rate in this study may be explained by the immediate positive effect exercise has on mouth opening ability and more importantly, the regression of MIO if training is absent.

The strengths of this study lie in its prospective study design as it is the only long-term follow-up study post jaw exercise training for trismus patients including both objective and subjective measures. It also has a large cohort and a small drop-out rate. It is of course limited by not being randomized allowing for selection bias, albeit this is minimized by the inclusion of a carefully matched control group.

\section{Clinical implications}

As trismus has a negative impact on function and HRQL, it is an important issue for clinicians to be aware of. This study has shown that jaw exercise therapy started early, in a structured manner and with continued training, appears to improve both MIO and HRQL —effects which appear stable up to 3 years.
Therefore, early identification of these patients with enrollment in structured exercise programs is advocated in an attempt to counteract post-radiotherapy trismus.

\section{Conclusions}

Jaw exercise therapy for irradiated $\mathrm{HNC}$ patients who develop trismus is effective up to 3 years after completion of the training and results in increased MIO, less trismus-related symptoms as well as improved HRQL. In order to maximize the results, jaw exercise therapy should be initiated early, in a structured manner and continued long term.

Acknowledgments We would like to thank oral surgeon Bodil Fagerberg-Mohlin at the Department of Oral and Maxillofacial Surgery, Institute of Odontology and Public Dental Service, Gothenburg, Sweden for performing all patient interventions, data collection, and expert advice.

Authors' contributions Caterina Finizia is mainly responsible for study conception and design. Material preparation, data collection, and analysis were performed by Ove Karlsson, Therese Karlsson, Nina Pauli, and Paulin Andréll. The first draft of the manuscript was written by Ove Karlssson and Nina Pauli and all authors commented on previous versions of the manuscript. All authors read and approved the final manuscript. 
Funding information Open Access funding provided by University of Gothenburg. This study was funded by the Swedish Cancer Society, the Research and Development Council (FoU), Västra Götaland County, Sweden, The Assar Gabrielsson Foundation Göteborg, and the Medical Faculty of Gothenburg University Sweden.

\section{Compliance with ethical standards}

Conflict of interest The authors declare that they have no conflicts of interest.

Ethical approval The study was approved by the Regional Ethical Review Board at Gothenburg University (287-04, T721-07, and T69417). All procedures performed in this study involving human participants were in accordance with the 1964 Helsinki declaration and its later amendments or comparable ethical standards. Informed consent was obtained from all individual participants included in the study.

Open Access This article is licensed under a Creative Commons Attribution 4.0 International License, which permits use, sharing, adaptation, distribution and reproduction in any medium or format, as long as you give appropriate credit to the original author(s) and the source, provide a link to the Creative Commons licence, and indicate if changes were made. The images or other third party material in this article are included in the article's Creative Commons licence, unless indicated otherwise in a credit line to the material. If material is not included in the article's Creative Commons licence and your intended use is not permitted by statutory regulation or exceeds the permitted use, you will need to obtain permission directly from the copyright holder. To view a copy of this licence, visit http://creativecommons.org/licenses/by/4.0/.

\section{References}

1. Dijkstra PU, Huisman PM, Roodenburg JL (2006) Criteria for trismus in head and neck oncology. Int J Oral Maxillofac Surg 35(4): $337-342$

2. Johnson J, Johansson M, Ryden A, Houltz E, Finizia C (2015) Impact of trismus on health-related quality of life and mental health. Head Neck 37(11):1672-1679

3. Pauli N, Johnson J, Finizia C, Andrell P (2013) The incidence of trismus and long-term impact on health-related quality of life in patients with head and neck cancer. Acta Oncol (Stockholm) 52(6):1137-1145

4. (2019) Nationellt vårdprogram för Huvud- och halscancer. Gothenburg: Regional Cancer Center West Sweden

5. Wang CJ, Huang EY, Hsu HC, Chen HC, Fang FM, Hsiung CY (2005) The degree and time-course assessment of radiation-induced trismus occurring after radiotherapy for nasopharyngeal cancer. Laryngoscope 115(8): 1458-1460

6. Buchbinder D, Currivan RB, Kaplan AJ, Urken ML (1993) Mobilization regimens for the prevention of jaw hypomobility in the radiated patient: a comparison of three techniques. J Oral Maxillofac Surg 51(8):863-867

7. Pauli N, Fagerberg-Mohlin B, Andrell P, Finizia C (2014) Exercise intervention for the treatment of trismus in head and neck cancer. Acta Oncol (Stockholm) 53(4):502-509

8. Kamstra JI, Roodenburg JL, Beurskens CH, Reintsema H, Dijkstra PU (2013) TheraBite exercises to treat trismus secondary to head and neck cancer. Supportive Care Cancer 21(4):951-957

9. Pauli N, Svensson U, Karlsson T, Finizia C (2016) Exercise intervention for the treatment of trismus in head and neck cancer - a prospective two-year follow-up study. Acta Oncol (Stockholm) 55(6):686-692

10. Bjordal K, de Graeff A, Fayers PM, Hammerlid E, van Pottelsberghe C, Curran D, Ahlner-Elmqvist M, Maher EJ, Meyza JW, Brédart A, Söderholm AL, Arraras JJ, Feine JS, Abendstein H, Morton RP, Pignon T, Huguenin P, Bottomly A, Kaasa S (2000) A 12 country field study of the EORTC QLQ-C30 (version 3.0) and the head and neck cancer specific module (EORTC QLQ-H\&N35) in head and neck patients. EORTC quality of life group. Eur J Cancer 36(14):1796-1807

11. Bjordal K, Hammerlid E, Ahlner-Elmqvist M, de Graeff A, Boysen M, Evensen JF, Biörklund A, de Leeuw JRJ, Fayers PM, Jannert M, Westin T, Kaasa S (1999) Quality of life in head and neck cancer patients: validation of the European Organization for Research and Treatment of Cancer Quality of Life Questionnaire-H\&N35. J Clin Oncol 17(3):1008-1019

12. Johnson J, Carlsson S, Johansson M, Pauli N, Ryden A, FagerbergMohlin B et al (2012) Development and validation of the Gothenburg Trismus Questionnaire (GTQ). Oral Oncol 48(8): 730-736

13. Paleri V, Wight RG (2002) Applicability of the adult comorbidity evaluation - 27 and the Charlson indexes to assess comorbidity by notes extraction in a cohort of United Kingdom patients with head and neck cancer: a retrospective study. J Laryngol Otol 116(3):200 205

14. Rogers SN, Aziz A, Lowe D, Husband DJ (2006) Feasibility study of the retrospective use of the adult comorbidity evaluation index (ACE-27) in patients with cancer of the head and neck who had radiotherapy. Br J Oral Maxillofac Surg 44(4):283-288

15. Paleri V, Wight RG, Silver CE, Haigentz M Jr, Takes RP, Bradley PJ, Rinaldo A, Sanabria A, Bień S, Ferlito A (2010) Comorbidity in head and neck cancer: a critical appraisal and recommendations for practice. Oral Oncol 46(10):712-719

16. Sobin L, Gospodarowicz M, Wittekind C (2009) TNM classification of malignant tumours. UICC International Union Against Cancer: Wiley-Blackwell

17. Pauli N, Andrell P, Johansson M, Fagerberg-Mohlin B, Finizia C (2015) Treating trismus: a prospective study on effect and compliance to jaw exercise therapy in head and neck cancer. Head Neck 37(12):1738-1744

18. Aaronson NK, Ahmedzai S, Bergman B, Bullinger M, Cull A, Duez NJ, Filiberti A, Flechtner H, Fleishman SB, Haes JCJM, Kaasa S, Klee M, Osoba D, Razavi D, Rofe PB, Schraub S, Sneeuw K, Sullivan M, Takeda F (1993) The European Organization for Research and Treatment of Cancer QLQ-C30: a quality-of-life instrument for use in international clinical trials in oncology. J Natl Cancer Inst 85(5):365-376

19. Fayers PMAN, Bjordal K, Groenvold M, Curran D, Bottomley A (2001) The EORTC QLQ-C30 scoring manual, 3rd edn. European Organisation for Research and Treatment of Cancer, Brussels

20. Kamstra JI, van Leeuwen M, Roodenburg JL, Dijkstra PU (2017) Exercise therapy for trismus secondary to head and neck cancer: a systematic review. Head Neck 39(1):160-169

21. Hammerlid E, Adnan A, Silander E (2017) Population-based reference values for the European Organization for Research and Treatment of Cancer Head and Neck module. Head Neck 39(10): 2036-2047

22. Hogdal N, Juhl C, Aadahl M, Gluud C (2015) Early preventive exercises versus usual care does not seem to reduce trismus in patients treated with radiotherapy for cancer in the oral cavity or oropharynx: a randomised clinical trial. Acta Oncol (Stockholm) 54(1):80-87

Publisher's note Springer Nature remains neutral with regard to jurisdictional claims in published maps and institutional affiliations. 